\title{
Research on Crack Resistance of Semi-flexible Pavement Materials
}

\author{
Wu Jiahong ${ }^{1}$ \\ ${ }^{1}$ Guangdong Transportation Planning and Design Institute Co., Ltd., Guangzhou, Guangdong, 510507 \\ Chinese Library Classification Number: U414 \\ Document Identification Code:
}

\begin{abstract}
Semi-flexible pavement has been widely used in China's road construction due to its excellent rutting resistance. Due to the large difference in volume stability between the matrix asphalt mixture and the cement mortar, the internal stress of the semi-flexible pavement material is concentrated and cracking is likely to occur. To explore the influence of different Influencing factors on the cracking resistance of semi-flexible pavement materials. This paper used the orthogonal design method to design the mix ratio of ordinary cement mortar. On this basis, admixtures (silica fume, ordinary emulsified asphalt, water-based epoxy resin) were added to prepare special cement mortar. Then, using cement mortar type, matrix porosity, matrix asphalt type, matrix aggregate type as the influencing factors, this article has studied his influence on the crack resistance of semi-flexible pavement materials. Tests show that cement mortar type, matrix porosity, matrix asphalt type, matrix aggregate type have varying degrees of influence on the crack resistance of semi-flexible pavement. The effect of matrix porosity on low temperature crack resistance is the greatest, followed by asphalt and cement mortar types, and the lowest by aggregate type. Enhancing the flexibility of cement mortar and enhancing the elastoplasticity of the matrix are conducive to improving the low-temperature performance of semi-flexible pavements.
\end{abstract}

\section{Introduction}

Semi-flexible pavement is a new type of pavement structure formed by pouring the high-performance cement mortar into the pavement structure with large voids. Since the structure is filled with cement mortar, the semi-flexible pavement has high structural strength and excellent rutting resistance ${ }^{1-4}$ 。 In recent years, semi-flexible pavements have been widely used in China's areas such as intersections, bus stations, and BRT lanes. ${ }^{5-7}$ Due to the large difference in volume stability between the base asphalt mixture and the cement mortar, when the cement mortar hydration reacts or temperature difference changes greatly, if the deformation of the base asphalt mixture and the cement mortar cannot be coordinated, stress concentration will appear in the semi-flexible pavement material, which is likely to crack, so the research on the crack resistance of semi-flexible pavement is particularly important $。$ Hu Shuguang ${ }^{8}$ adopted both the water reducing agent and the expansion agent to optimize cement mortar performance and semi-flexible pavement crack resistance. The influence of chemical shrinkage reducer and water reducers of various functions on the performance of cement mortar was discussed by Cai Anlan ${ }^{9} \mathrm{Hu}$ Shuguang ${ }^{10}$ analyzed the influential factors of the volume stability and crack resistance of semi-flexible pavement, and develop polymer cement mortar with strong fluidity and small shrinkage deformation. The low-temperature crack resistance of semi-flexible pavement materials was systematically studied and evaluated by Zhang Dake, Cheng Changqing, Wu Guoxiong and so on ${ }^{11}$. Wang Weiming ${ }^{12}$ used three-point semicircle bending test to evaluate the crack resistance of semi-flexible road surface. Based on the internal stress control method, the internal cracking mechanism of semi-flexible pavement materials was explored by Wang Duanyi and so on ${ }^{13}$.

The structural characteristics and material types of semi-flexible pavement materials have different degrees of impact on the anti-cracking performance. This paper first obtains the mix ratio of ordinary cement mortar based on orthogonal experiments, and then selects silica fume, emulsified asphalt, and water-based epoxy resin as cement mortar admixtures from the perspective of engineering application, and optimizes the performance of cement mortar, prepare three kinds of special cement mortars, and finally makes analysis on the anti-cracking performance of semi-flexible pavement with the cement mortar type, the matrix void ratio, the matrix aggregate type, the matrix asphalt type as influential factors, providing operability technical reference for the optimization of crack resistance of semi-flexible pavement. 
2 Preparation of raw materials

\subsection{Cement}

The test adopts P.O32.5 Portland cement, and its performance is tested according to the specification 14 as shown in Table 1.

Tab.1 P.O 32.5 performance index

\begin{tabular}{c|c|c|c|c|c|c|c}
\hline \multirow{2}{*}{ Index } & \multirow{2}{*}{ Fineness } & \multicolumn{2}{|c|}{$\begin{array}{c}\text { Compressive strength } \\
(\mathrm{MPa})\end{array}$} & \multicolumn{2}{c|}{$\begin{array}{c}\text { Flexural strength } \\
(\mathrm{MPa})\end{array}$} & \multirow{2}{*}{$\begin{array}{c}\text { Initial setting } \\
\text { time }(\mathrm{min})\end{array}$} & $\begin{array}{c}\text { Final setting } \\
\text { time }(\mathrm{min})\end{array}$ \\
\cline { 3 - 7 } & & $7 \mathrm{~d}$ & $28 \mathrm{~d}$ & $7 \mathrm{~d}$ & $28 \mathrm{~d}$ & & 350 \\
\hline P.O32.5 & 1.2 & 25.5 & 36.1 & 175 & 350 & 175 & 350 \\
\hline
\end{tabular}

Standard sand is used for the molding cement mortar in

2.2 Standard sand this test, and its gradation is shown in Table 1.

Tab. 2 The gradation of standard sand

\begin{tabular}{c|c|c|c|c|c|c}
\hline Sieve size & 1.18 & 0.6 & 0.3 & 0.15 & 0.075 & $\begin{array}{c}\text { Mud content } \\
(\%)\end{array}$ \\
\hline Pass rate (\%) & 100 & 97.2 & 90.5 & 53.6 & 2.5 & 0.4 \\
\hline
\end{tabular}

\subsection{Mineral powder}

Limestone ore powder was used as the base asphalt mixture in this test, as shown in Table 2 below.

Tab. 3 Powdered ore quality technical specification

\begin{tabular}{c|c|c|c|c|c|c}
\hline Test item & $\begin{array}{c}\text { Apparent } \\
\text { density } \\
(\mathrm{g} / \mathrm{cm} 3)\end{array}$ & $\begin{array}{c}\text { Water } \\
\text { content } \\
(\%)\end{array}$ & \multicolumn{4}{|c}{ Screening test } \\
\hline Test result & 2.65 & 0.23 & Mesh size $(\mathrm{mm})$ & 0.3 & 0.15 & 0.075 \\
\hline $\begin{array}{c}\text { Technical } \\
\text { standard }\end{array}$ & $\geq 2.5$ & $\leq 1$ & Pass rate $(\%)$ & 100 & 97.7 & 87.5 \\
\hline
\end{tabular}

\subsection{Admixture}

(1) The composition and index of silica fume are shown in Table 4.

Tab. 4 Pulverized coal ash chemical composition and index

\begin{tabular}{c|c|c|c}
\hline Item & Evaluation Standard & Test Results & Individual Evaluation \\
\hline $\begin{array}{c}\text { Total alkali content } \\
(\%)\end{array}$ & $\leq 1.5$ & 1.0 & qualified \\
\hline SiO2 content $(\%)$ & $\geq 85.0$ & 87.5 & qualified \\
\hline $\begin{array}{c}\text { Chlorine content } \\
(\%)\end{array}$ & $\leq 0.1$ & 0.7 & qualified \\
\hline $\begin{array}{c}\text { Moisture content } \\
(\text { powder }(\%)\end{array}$ & $\leq 3.0$ & 2.1 & qualified \\
\hline Ignition loss $(\%)$ & $\leq 4.0$ & 3.2 & qualified \\
\hline
\end{tabular}

(2) The components and indexes of emulsified asphalt are shown in Table 5.

Tab. 5 Emulsified asphalt technical specification

\begin{tabular}{c|c|c|c|c}
\hline Test item & Unit & $\begin{array}{c}\text { Design } \\
\text { evaluation } \\
\text { standard }\end{array}$ & Test result & $\begin{array}{c}\text { Individual } \\
\text { evaluation }\end{array}$ \\
\hline The remaining amount on the sieve & $\%$ & $\leq 0.1$ & 0.02 & qualified \\
\hline
\end{tabular}




\begin{tabular}{|c|c|c|c|c|c|}
\hline \multicolumn{2}{|r|}{ Charge } & - & Cation (+) & $\begin{array}{c}\text { Cation } \\
\text { Qualified }\end{array}$ & qualified \\
\hline \multicolumn{2}{|c|}{ Demulsification speed } & - & slow cracking & $\begin{array}{c}\text { slow } \\
\text { cracking }\end{array}$ & qualified \\
\hline \multicolumn{2}{|c|}{$\begin{array}{l}\text { Viscosity (Asphalt Standard } \\
\text { Viscometer C25,3) }\end{array}$} & $\mathrm{s}$ & $12 \sim 60$ & 25 & qualified \\
\hline \multirow{5}{*}{$\begin{array}{l}\text { evaporatio } \\
\mathrm{n} \text { the } \\
\text { remains }\end{array}$} & Content & $\%$ & $\geq 62$ & 63.5 & qualified \\
\hline & Penetration $\left(25^{\circ} \mathrm{C}\right)$ & $0.1 \mathrm{~mm}$ & $40 \sim 100$ & 70 & qualified \\
\hline & $\begin{array}{c}\text { Softening point } \\
\text { TR\&B } \\
\end{array}$ & ${ }^{\circ} \mathrm{C}$ & $\geq 57$ & 58.0 & qualified \\
\hline & $\operatorname{Ductility}\left(5^{\circ} \mathrm{C}\right)$ & $\mathrm{cm}$ & $\geq 20$ & 23 & qualified \\
\hline & Solubility & $\%$ & $\geq 97.5$ & 99.3 & qualified \\
\hline \multirow{2}{*}{$\begin{array}{c}\text { Store } \\
\text { Stability }\end{array}$} & $1 d$ & $\%$ & $\leq 1$ & 0.28 & qualified \\
\hline & $5 d$ & $\%$ & $\leq 5$ & 3.29 & qualified \\
\hline
\end{tabular}

(3) The components and indexes of water-based epoxy resin are shown in Table 6.

Tab.6 Performance index of waterborne epoxy resin

\begin{tabular}{|c|c|c|c|}
\hline Item & Test result & Standard & Test method \\
\hline \multirow[b]{2}{*}{ Viscosity $\left(\mathrm{Pa} \cdot \mathrm{s}, 20^{\circ} \mathrm{C}\right)$} & 452 & A component $(100 \sim 600)$ & \multirow[b]{2}{*}{ GB/T 9751} \\
\hline & 73 & B component $(50 \sim 80)$ & \\
\hline \multirow{2}{*}{ Fineness $(\mu \mathrm{m}), \leq$} & 38.8 & A component $(40)$ & \multirow[b]{2}{*}{ GB/T 1724} \\
\hline & 39 & B component $(40)$ & \\
\hline \multirow[b]{2}{*}{ Solid content $(\%)$} & 50.2 & A component $(50 \pm 2)$ & \multirow[b]{2}{*}{ GB/T 1725} \\
\hline & 50.7 & B component $(50 \pm 2)$ & \\
\hline Surface drying time $\left(\min , 20^{\circ} \mathrm{C}\right), \geq$ & 140 & 120 & GB/T 1728 \\
\hline Coating hardness, $\geq$ & 0.50 & 0.49 & GB/T 1730 \\
\hline Adhesion (level) & 2 & $1 \sim 2$ & GB/T 1720 \\
\hline
\end{tabular}

\subsection{Asphalt}

The technical performance of the asphalt used in this test is shown in Table 7 below.

Tab. 7 Asphalt technical indicators

\begin{tabular}{l|l|l|l|l}
\hline Test item & Test item & $\begin{array}{l}\text { Matrix } \\
\text { asphalt }\end{array}$ & $\begin{array}{l}\text { SBS modified } \\
\text { asphalt }\end{array}$ & $\begin{array}{l}\text { Epoxy } \\
\text { modified } \\
\text { asphalt }\end{array}$ \\
\hline Penetration $25^{\circ} \mathrm{C}, 100 \mathrm{~g}, 5 \mathrm{~s}$ & $0.1 \mathrm{~mm}$ & 73.6 & 63.5 & 58.2 \\
\hline Softening point TR\&B & ${ }^{\circ} \mathrm{C}$ & 60.5 & 79.0 & 91.2 \\
\hline Ductility $5^{\circ} \mathrm{C}, 5 \mathrm{~cm} / \mathrm{min}$ & $\mathrm{cm}$ & 30 & 38 & 23 \\
\hline Density $15^{\circ} \mathrm{C}$ & $\mathrm{g} / \mathrm{cm} 3$ & 1.059 & 1.033 & 1.043 \\
\hline Solubility (trichloroethylene) & $\% \mathrm{wt}$ & 99.97 & 101.3 & 100.4 \\
\hline Flash point (COC) & ${ }^{\circ} \mathrm{C}$ & 284 & 275 & 280 \\
\hline Wax content & $\% \mathrm{wt}$ & 1.70 & 1.70 & 1.68 \\
\hline
\end{tabular}




\subsection{Aggregate}

The technical properties of aggregates used in this experiment are shown in Table 8 below.

Tab. 8 Aggregate performance

\begin{tabular}{c|c|c|c|c}
\hline Item & Limestone & Tuff & Basalt & $\begin{array}{c}\text { Technical Index } \\
\text { Requirements }\end{array}$ \\
\hline $\begin{array}{c}\text { Crush value/\% } \\
\begin{array}{c}\text { Los Angeles wear } \\
\text { value/\% }\end{array}\end{array}$ & 13 & 10.5 & 9.2 & $\leq 26$ \\
\hline $\begin{array}{c}\text { Needle flake content/\% } \\
\text { Sand equivalen/\% }\end{array}$ & 4.5 & 12 & 11.4 & $\leq 28$ \\
\hline $\begin{array}{c}\text { Stone polishing } \\
\text { value/BPN }\end{array}$ & 77 & 6.8 & 5.6 & $\geq 60$ \\
\hline Robustness/\% & 85 & 48 & 51 & $\geq 42$ \\
\hline
\end{tabular}

\section{Design of cement mortar mix ratio}

\subsection{Orthogonal experimental design}

Tab.9 performance requirement of cement mortar

\begin{tabular}{l|l|l}
\hline Index & Range & Condition \\
\hline Compressive strength $(\mathrm{MPa})$ & $10 \sim 30$ & \multirow{3}{*}{ Cure for 7 days under standard } \\
\cline { 1 - 2 } Flexural strength $(\mathrm{MPa})$ & $>3.0$ & \\
\hline conditions Fluidity $(\mathrm{s})$ & $10 \sim 14$ & \\
\hline
\end{tabular}

According to existing research ${ }^{15-16}$, cement mortar is generally composed of water, cement, standard sand and mineral powder. The performance of cement mortar is affected by the factors of water-cement ratio, mineral powder dosage and standard sand dosage. In order to simplify the test design, this paper designs different watercement ratio, slag powder dosage and standard sand

Tab10 Orthogonal test design

\begin{tabular}{l|l|l|l}
\hline Level & A Water-cement ratio & $\begin{array}{l}\text { B Mineral powder } \\
\text { consumption (\%) }\end{array}$ & $\begin{array}{l}\text { C Standard sand } \\
\text { consumption }(\%)\end{array}$ \\
\hline 1 & 0.5 & 4 & 8 \\
\hline 2 & 0.6 & 8 & 16 \\
\hline 3 & 0.7 & 12 & 24 \\
\hline
\end{tabular}

Tab.11 L9 $\left(3^{3}\right)$ orthogonal Table

\begin{tabular}{l|l|l|l}
\hline Test number & A Water-cement ratio & $\begin{array}{l}\text { B Mineral powder } \\
\text { consumption }(\%)\end{array}$ & $\begin{array}{l}\text { C Standard sand } \\
\text { consumption }(\%)\end{array}$ \\
\hline 1 & 0.5 & 4 & 8 \\
\hline 2 & 0.5 & 8 & 16 \\
\hline 3 & 0.5 & 12 & 24 \\
\hline 4 & 0.60 & 4 & 16 \\
\hline 5 & 0.60 & 8 & 24 \\
\hline 6 & 0.60 & 12 & 8 \\
\hline 7 & 0.7 & 4 & 24 \\
\hline 8 & 0.7 & 8 & 8 \\
\hline 9 & 0.7 & 12 & 16 \\
\hline
\end{tabular}

dosage parameters for orthogonal design, and prepares the corresponding cement mortar. And combined with the specification requirements, test the fluidity, strength and shrinkage index of cement mortar. Orthogonal design table is shown in the following tables 10 and 11 , and the test data is shown in table12
This test refers to the index requirements of the Japan Road Association "Common Official Sample Book Explanation for Assforut Paving Works", as shown in Table 9. 
Tab.12 Ordinary cement mortar test results

\begin{tabular}{l|l|l|l|l}
\hline \multirow{2}{*}{ No } & \multirow{2}{*}{ Fluidity $(\mathrm{s})$} & \multicolumn{2}{|l|}{ 7-day strength $(\mathrm{MPa})$} & \multirow{2}{*}{$\begin{array}{l}\text { 28d dry shrinkage } \\
\text { nnynn}\end{array}$} \\
\cline { 3 - 4 } & & Flexural & resistance & 241 \\
\hline 1 & 15.52 & 2.22 & 15.1 & 182 \\
\hline 2 & 19.45 & 3.43 & 25.05 & 215 \\
\hline 3 & 26.98 & 4 & 28.23 & 197 \\
\hline 4 & 14.64 & 2.35 & 14.65 & 170 \\
\hline 5 & 17.68 & 3.12 & 18.38 & 191 \\
\hline 6 & 15.55 & 3.05 & 20.12 & 203 \\
\hline 7 & 10.32 & 2.37 & 16.28 & 200 \\
\hline 8 & 9.01 & 3.25 & 20.47 & 151 \\
\hline 9 & 13.4 & 2.77 & 17.32 & \\
\hline
\end{tabular}

The range analysis of cement mortar fluidity data is shown

3.2 Test analysis in Table13 below.

Tab.13 Range analysis on mobility of cement mortar

\begin{tabular}{l|l|l|l}
\hline Index & Liquidity & \multicolumn{2}{l}{ B Mineral powder } \\
Factor & A Water-cement ratio & $\begin{array}{l}\text { C Standard sand } \\
\text { consumption }\end{array}$ \\
\hline$K_{1 j}$ & 61.95 & 40.48 & 40.08 \\
\hline$K_{2 j}$ & 47.87 & 46.14 & 47.49 \\
\hline$K_{3 j}$ & 32.73 & 55.93 & 54.98 \\
\hline$\overline{K_{1 j}}$ & 20.65 & 13.49 & 13.36 \\
\hline$\overline{K_{2 j}}$ & 15.96 & 15.38 & 15.83 \\
\hline$\overline{K_{3 j}}$ & 10.91 & 18.64 & 18.33 \\
\hline$R_{j}$ & 9.74 & 5.15 & 4.07 \\
\hline Sensitivity & $(\mathrm{A}>\mathrm{B}>\mathrm{C})$ & $\mathrm{R} 1>\mathrm{R} 2>\mathrm{R} 3$ & \multicolumn{1}{l}{} \\
\hline Optimal level & 3 & 1 & 1 \\
\hline
\end{tabular}

From the data analysis in Table 25, it can be seen that only the fluidity index is used as a reference, the best mixing ratio of cement mortar is: water-cement ratio of 0.7 , the amount of mineral powder $4 \%$ and the amount of standard sand $8 \%$. This shows that the water-cement ratio

Tab.14 Range analysis on $7 \mathrm{~d}$ strength of cement mortar

\begin{tabular}{c|l|l|l|l|l|l}
\hline Index & \multicolumn{4}{l|}{ 7d flexural strength } & \multicolumn{4}{l}{ 7d compressive strength } \\
\hline Factors & $\begin{array}{l}\text { A Water- } \\
\text { cement ratio }\end{array}$ & $\begin{array}{l}\text { B Mineral } \\
\text { powder } \\
\text { consumption }\end{array}$ & $\begin{array}{l}\text { C Standard } \\
\text { sand } \\
\text { consumption }\end{array}$ & $\begin{array}{l}\text { A Water- } \\
\text { cement ratio }\end{array}$ & $\begin{array}{l}\text { B Mineral } \\
\text { powder } \\
\text { consumption }\end{array}$ & $\begin{array}{l}\text { C Standard } \\
\text { sand } \\
\text { consumption }\end{array}$ \\
\hline$K_{1 j}$ & 10.15 & 8.44 & 9.02 & 68.38 & 46.03 & 55.69 \\
\hline$K_{2 j}$ & 9.02 & 9.8 & 9.25 & 53.15 & 63.9 & 57.02 \\
\hline$K_{3 j}$ & 9.09 & 10.02 & 9.99 & 54.07 & 65.67 & 62.89 \\
\hline$\overline{K_{1 j}}$ & 3.38 & 2.81 & 3.01 & 22.79 & 15.34 & 18.56 \\
\hline$\overline{K_{2 j}}$ & 3.01 & 3.27 & 3.08 & 17.72 & 21.3 & 19.01 \\
\hline$\overline{K_{3 j}}$ & 3.03 & 3.34 & 3.33 & 18.02 & 21.89 & 20.96 \\
\hline$R_{j}$ & 0.37 & 0.53 & 0.32 & 5.07 & 6.55 & 2.40 \\
\hline Sensitivity & $(\mathrm{B}>\mathrm{A}>\mathrm{C})$ & $\mathrm{R}_{2}>\mathrm{R}_{1}>\mathrm{R}_{3}$ & & $(\mathrm{~B}>\mathrm{A}>\mathrm{C}) \quad \mathrm{R}_{2}>\mathrm{R}_{1}>\mathrm{R}_{3}$ & \\
\hline $\begin{array}{l}\text { Optimal } \\
\text { level }\end{array}$ & 1 & 3 & 3 & 1 & 3 & 3 \\
\hline
\end{tabular}

index has the most significant impact on the flow properties of cement mortar. The range analysis of the $7 d$ strength of cement mortar is carried out, as shown in Table 14 below. 
It can be seen from Table 2-6 that taking $7 \mathrm{~d}$ flexural strength and $7 \mathrm{~d}$ compressive strength as references, the best mix ratio of cement mortar is: water-cement ratio 0.5 , mineral powder dosage $12 \%$ and standard sand dosage $24 \%$. This shows that the amount of mineral powder has the most significant impact on the strength performance of cement mortar, followed by the water-cement ratio, and the amount of standard sand has the least impact. The dry shrinkage of cement mortar is analyzed with extreme difference, as shown in the following table 15.

Tab. 15 Range analysis on contraction of cement mortar

\begin{tabular}{|c|c|c|c|}
\hline \multirow{2}{*}{$\begin{array}{l}\text { Index } \\
\text { Factors }\end{array}$} & \multicolumn{3}{|l|}{ Dry shrinkage } \\
\hline & A Water-cement ratio & $\begin{array}{l}\text { B Mineral powder } \\
\text { consumption }\end{array}$ & $\begin{array}{l}\text { C Standard sand } \\
\text { consumption }\end{array}$ \\
\hline$K_{1 j}$ & 638 & 641 & 632 \\
\hline$K_{2 j}$ & 558 & 552 & 530 \\
\hline$K_{3 j}$ & 554 & 557 & 588 \\
\hline$\overline{\overline{K_{1 j}}}$ & 212.67 & 213.67 & 210.67 \\
\hline$\overline{\overline{K_{2 j}}}$ & 186 & 184 & 176.67 \\
\hline$\overline{K_{3 j}}$ & 184.67 & 185.67 & 196 \\
\hline$R_{j}$ & 28.0 & 28.67 & 34.0 \\
\hline Sensitivity & \multicolumn{3}{|c|}{$(\mathrm{C}>\mathrm{B}>\mathrm{A}) \quad \mathrm{R}_{3}>\mathrm{R}_{2}>\mathrm{R}_{1}$} \\
\hline Optimal level & 3 & 2 & 2 \\
\hline
\end{tabular}

It can be seen from the analysis of the range of dry shrinkage in Table 2-7 that, taking dry shrinkage as a reference, the best mix ratio of cement mortar is: watercement ratio 0.7 , slag dosage $8 \%$ and standard sand dosage $16 \%$. This shows that the water-cement ratio index has the most significant influence on the shrinkage performance of cement mortar, and the importance of the two factors of the amount of mineral powder and the amount of standard sand is not much different.

\subsection{Determine the best mix ratio}

According to the orthogonal test analysis, the fluidity of mortar increases with the increase of water-cement ratio, and meets the requirements of fluidity specification when the water-cement ratio is $0.62 \sim 0.7$; the strength of mortar decreases as the water-cement ratio increases, but When the water-cement ratio is 0.5 to 0.7 , the strength value can meet the specification requirements; the shrinkage performance of the mortar has little effect with the increase of the water-cement ratio, and when the watercement ratio is 0.7 , the mortar shrinkage value is the smallest. Therefore, the recommended mortar watercement ratio is 0.7 .

The amount of mineral powder has a greater impact on the fluidity of the mortar. The larger the amount of mineral powder, the fluidity of the mortar becomes weaker; it has a greater impact on the strength of $7 \mathrm{~d}$ and $28 \mathrm{~d}$, but an appropriate amount of mineral powder can help improve the strength of the mortar; The amount of mineral powder also has a greater impact on the shrinkage performance of the mortar. When the amount of mineral powder is $9 \%$, the dry shrinkage of the mortar reaches the minimum. Considering the mortar powder consumption is $8 \%$.

The amount of standard sand has the least influence on the strength and fluidity of the mortar. When the amount of standard sand is larger, the fluidity of the mortar is weaker and the strength is lower; an appropriate amount of standard sand can reduce the shrinkage of the mortar. It was finally decided that the standard sand dosage was $16 \%$ In summary, the mix ratio of cement mortar designed by orthogonal experiment is: water-cement ratio is 0.7 , standard sand dosage is $16 \%$, and mineral powder dosage is $8 \%$.

\section{Optimization design of cement mortar mix ratio}

There are many admixtures in the target market that can significantly improve the relative performance of cement mortar. In order to further improve the performance of cement mortar and semi-flexible pavement, based on the design of cement mortar mix ratio, this study uses three admixtures of silica fume, emulsified asphalt and waterborne epoxy resin to optimize the mix ratio design of cement mortar. The optimized design scheme and test results are shown in Tables16 and 17.

Tab.16 Cement mortar optimization allocated proportion design

\begin{tabular}{l|l|l|l|l|l|l}
\hline No & $\begin{array}{l}\text { Water-cement } \\
\text { ratio }\end{array}$ & $\begin{array}{l}\text { Mineral } \\
\text { powder \% }\end{array}$ & $\begin{array}{l}\text { Sand } \\
\text { consumption \% }\end{array}$ & $\begin{array}{l}\text { Silica fume } \\
\text { Percentage } \\
\text { of cement } \%\end{array}$ & $\begin{array}{l}\text { Emulsified asphalt } \\
\text { accounts for } \\
\text { Percentage } \\
\text { of cement } \%\end{array}$ & $\begin{array}{l}\text { Waterborne epoxy } \\
\text { resin accounts for } \\
\text { Percentage of } \\
\text { cement \% }\end{array}$ \\
\hline (1) & 0.7 & 8 & 16 & 0 & 0 & 0 \\
\hline (2) & 0.7 & 8 & 16 & 5 & 0 & 0 \\
\hline (3) & 0.7 & 8 & 16 & 10 & 0 & 0 \\
\hline
\end{tabular}




\begin{tabular}{l|l|l|l|l|l|l}
\cline { 5 - 7 }$(4)$ & 0.7 & 8 & 16 & 15 & 0 & 0 \\
\hline$(5)$ & 0.7 & 8 & 16 & 0 & 4 & 0 \\
\hline$(6)$ & 0.7 & 8 & 16 & 0 & 8 & 0 \\
\hline$(7)$ & 0.7 & 8 & 16 & 0 & 12 & 0 \\
\hline$(8)$ & 0.7 & 8 & 16 & 0 & 0 & 3 \\
\hline$(9)$ & 0.7 & 8 & 16 & 0 & 0 & 6 \\
\hline$(10$ & 0.7 & 8 & 16 & 0 & 0 & 9 \\
\hline
\end{tabular}

Tab.17 Cement mortar optimization test results

\begin{tabular}{l|l|l|l|l}
\hline \multirow{2}{*}{ No } & \multirow{2}{*}{ Fluidity $(\mathrm{s})$} & \multicolumn{2}{|l|}{ 7-day strength $(\mathrm{MPa})$} & \multirow{2}{*}{ Dry shrinkage $(0.001 \mathrm{~mm})$} \\
\cline { 3 - 4 } & & Flexural & resistance & \\
\hline$(1)$ & 11.1 & 3.58 & 18.2 & 135 \\
\hline$(2)$ & 9.8 & 4.14 & 20.4 & 130 \\
\hline$(3)$ & 11.8 & 4.41 & 21.99 & 124 \\
\hline$(4)$ & 14.3 & 4.93 & 23.33 & 118 \\
\hline$(5)$ & 11.2 & 4.58 & 17.1 & 121 \\
\hline$(6)$ & 14 & 4.73 & 16 & 108 \\
\hline$(7)$ & 17.5 & 4.95 & 15.3 & 112 \\
\hline$(8)$ & 10.8 & 4.75 & 25.12 & 110 \\
\hline$(9)$ & 9.51 & 4.91 & 28.24 & 82 \\
\hline$(10)$ & 8.33 & 5.21 & 31.45 & 94 \\
\hline
\end{tabular}

(1) It can be seen from Table17 that the amount of silica fume is $0-15 \%$, the amount of emulsified asphalt is $0-8 \%$, and the amount of water-based epoxy resin is 0 $10 \%$. The fluidity meets the specification requirements. The amount of silica fume and fluidity are parabolic, and the fluidity shows a trend of first decreasing and then increasing, which indicates that there is an optimal value for the amount of silica fume, that is, when the amount of silica fume is $5 \%$, the fluidity reaches a minimum; and The amount of emulsified asphalt is positively correlated with fluidity index, and the amount of water-based epoxy resin is negatively correlated with fluidity.

(2) It can be seen from Table 17 that the incorporation of silica fume, emulsified asphalt and water-based epoxy resin can all improve the flexural strength of cement mortar; the incorporation of silica fume and water-based epoxy resin can improve the resistance of cement mortar Compressive strength, but the incorporation of emulsified asphalt reduces the compressive strength. From the data analysis, it is known that the flexural strength of cement mortar slowly increases after the emulsified asphalt is mixed with the external admixture, but the compressive strength shows a downward trend, indicating that emulsified asphalt can reduce the flexural ratio of cement mortar. Since cement mortar is a rigid material, and the asphalt mixture matrix is a flexible material, reducing the buckling ratio of cement mortar can increase the flexibility of cement mortar, which is very beneficial to the crack resistance and durability of semi-flexible pavements. Data calculations show that silica fume also reduces the compression ratio of cement mortar, while water-based epoxy resin increases the compression ratio of cement mortar. To sum up, silica fume and emulsified asphalt can improve the flexibility of cement mortar, while water- based epoxy resin improves the brittleness of cement mortar.

(3) It can be seen from Table 17 that the mixing of silica fume, emulsified asphalt and water-based epoxy resin further reduces the shrinkage of cement mortar. The greater the mixing, the greater the decrease in the shrinkage of cement mortar. It is advantageous to improve the shrinkage properties of cement mortar. However, from the data analysis, it is known that the incorporation of water-based epoxy resin has the largest reduction in the shrinkage of cement mortar, followed by emulsified asphalt, and silica fume is the smallest. This shows that waterborne epoxy resin has the greatest impact on reducing the shrinkage of cement mortar and can be used as an admixture to improve the shrinkage of cement mortar. Considering the influence of fluidity, strength and shrinkage performance, three optimized cement mortars are finally designed. The mixing ratio of cement mortar I is: water-cement ratio 0.7 , standard sand consumption $16 \%$, mineral powder consumption $8 \%$, and emulsified asphalt $4 \%$; The mixing ratio of cement mortar II is: water-cement ratio 0.7 , standard sand consumption $16 \%$, mineral powder consumption $8 \%$, silica fume $5 \%$; the mixing ratio of cement mortar III: water-cement ratio 0.7 , standard sand consumption $16 \%$, The amount of mineral powder is $8 \%$, and the water-based epoxy resin is $6 \%$, which is used for the subsequent semi-flexible road grouting material.

\section{Grading design of base asphalt mixture}

In this study, the main aggregate void filling method 
(CAVF) ${ }^{18-19}$ was used to design the gradation of porous asphalt mixture. The main mechanism of the CAVF method is to first determine the interstitial ratio of the main skeleton of the coarse aggregate, so that the sum of the asphalt, fine aggregate, mineral powder and the designed pore volume is equal to the pore volume of the main skeleton. The gradation of the matrix mixture is shown in Table18.

Tab.18 The gradation of the matrix asphalt mixture

\begin{tabular}{c|c|c|c|c|c|c|c|c|c|c|c}
\hline $\begin{array}{c}\text { Mesh } \\
\text { Pass rate }\end{array}$ & 19 & 16 & 13.2 & 9.5 & 4.75 & 2.36 & 1.18 & 0.6 & 0.3 & 0.15 & 0.075 \\
\hline $24 \%$ & 100 & 75.1 & 55.5 & 19.3 & 18.4 & 15.7 & 13.9 & 12.0 & 8.4 & 5.2 & 3.0 \\
\hline $28 \%$ & 100 & 73.1 & 52.3 & 14.6 & 12.0 & 10.6 & 9.6 & 8.2 & 6.2 & 4.3 & 2.9 \\
\hline $32 \%$ & 100 & 71.2 & 49.9 & 8.5 & 7.5 & 6.6 & 6.2 & 5.6 & 4.5 & 3.5 & 2.9 \\
\hline
\end{tabular}

\section{Anti-crack performance test analysis}

\subsection{Low temperature bending test}

(4) In this study, the low-temperature bending test ${ }^{20-21}$ was used to analyze the crack resistance performance of semiflexible pavement materials. The test conditions were: test temperature $-10^{\circ} \mathrm{C}$ and loading rate $5 \mathrm{~mm} / \mathrm{min}$. According to formulas 1 to 3 , the flexural tensile strength, maximum flexural tensile strain and flexural stiffness modulus of the specimen at failure are calculated, which are used as the evaluation index of crack resistance for subsequent analysis.

$$
\begin{gathered}
R_{B}=\frac{3 L P_{B}}{2 b h^{2}} \\
\varepsilon_{B}=\frac{6 h d}{L^{2}}
\end{gathered}
$$

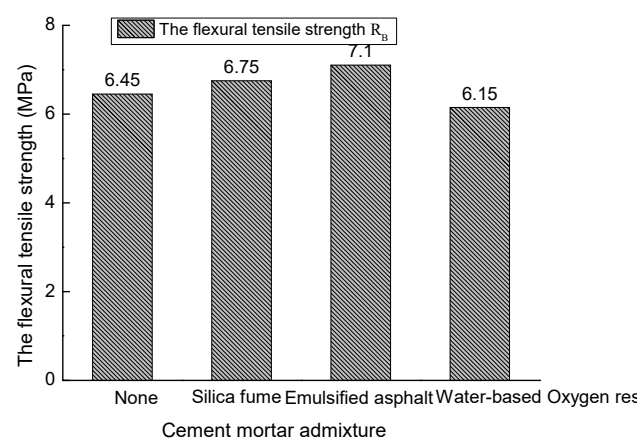

(a)

$$
S_{B}=\frac{R_{B}}{\varepsilon_{B}}
$$

Where: $R_{B} 、 \varepsilon_{B} 、 S_{B}$ are respectively the flexural tensile strength $(\mathrm{MPa})$, the maximum flexural tensile strain, and the bending stiffness modulus (MPa); $b, h$ are the width $(\mathrm{mm})$ and height $(\mathrm{mm})$; PB and $\mathrm{d}$ are the maximum load $(\mathrm{N})$ and mid-span deflection $(\mathrm{mm})$ of the specimen failure respectively.

\subsection{Influence of cement mortar admixture}

The semi-flexible pavement matrix mixture is prepared with a grading curve with a porosity of $24 \%$, matrix asphalt, and tuff aggregate. Then, ordinary cement mortar and three kinds of cement mortars with special properties (silica fume $5 \%$, emulsified asphalt $4 \%$, water-based Oxygen resin $6 \%$ ) is poured into the substrate to form semi-flexible road parts, and conduct low temperature bending test. The test results are shown in the figure below.

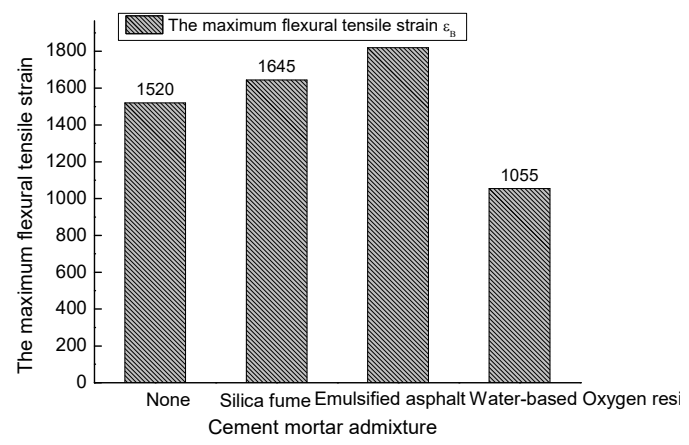

(b) 


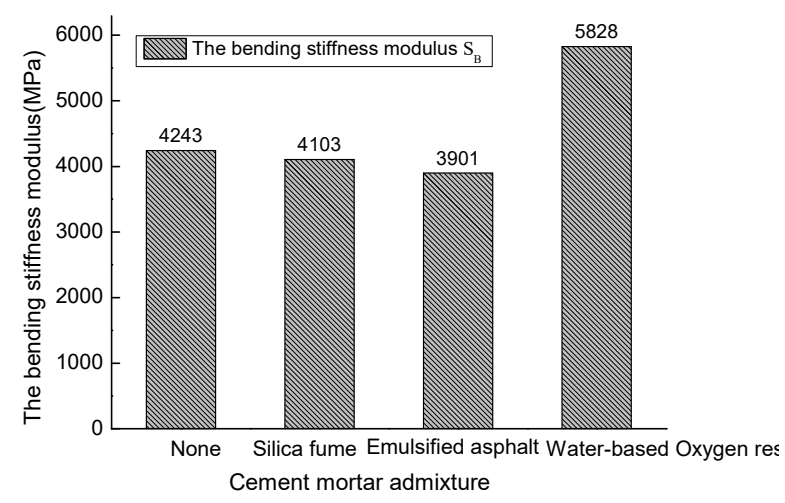

(c)

Figure 1 The results of low temperature bend test

From the data in Figure 1:

When the matrix void ratio is $24 \%$, the cement mortar mixed with silica fume, emulsified asphalt and waterbased epoxy resin will have a certain degree of influence on the flexural tensile strength of semi-flexible pavement materials. Among them, the emulsified asphalt and silica fume improve The maximum bending tensile strain and bending tensile strength of the original semi-flexible pavement material are reduced, and the bending stiffness modulus is reduced; while the water-based epoxy resin reduces its bending tensile strength and maximum bending tensile strain and improves the bending stiffness modulus. the amount. This indicates that emulsified asphalt and silica fume improve the crack resistance of semi-flexible pavement. Among them, emulsified asphalt has a stronger correlation with the crack resistance of semi-flexible pavement. Water-based epoxy resin reduces the crack resistance of the original semi-flexible pavement. From the perspective of engineering application, the method of mixing cement mortar with emulsified asphalt can be used to improve the crack resistance of semi-flexible pavement materials. Analysis of the reasons shows that water-based epoxy resin is a thermosetting material, which improves the strength and rigidity of cement mortar, further increases the modulus ratio of cement mortar and base asphalt mixture, and intensifies cement mortar and base asphalt mixture. The volume coordination of the cement mortar and the base asphalt mixture makes the interface between the cement mortar and the base asphalt mixture easier to crack, and the cooperative deformation ability is

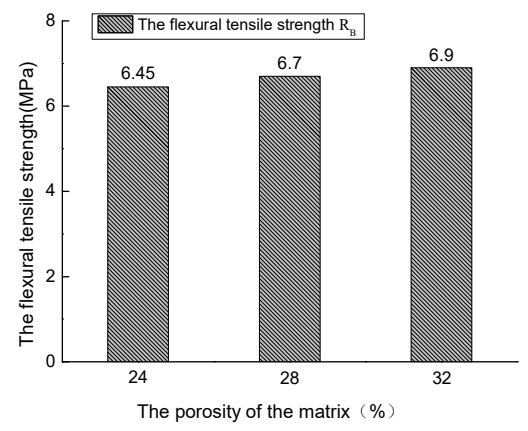

(a) weaker. Therefore, the incorporation of water-based epoxy resin increases the cracking susceptibility of the semiflexible pavement material. It also indirectly shows that water-based epoxy resin can be used to improve the strength and fluidity of cement mortar, but it is not suitable for improving the crack resistance of semi-flexible pavement materials. The silica fume has high fineness, smooth surface, and has a certain lubricating effect, which can improve the compactness of cement mortar and improve the volume stability of cement mortar, which is beneficial to the anti-cracking performance of semiflexible pavement; emulsified asphalt can improve cement The flexibility of the mortar enhances the volumetric synergistic deformation capacity of the cement mortar and the semi-flexible pavement matrix, thereby improving the crack resistance of the semi-flexible pavement structure. Therefore, the incorporation of silica fume and emulsified asphalt has a significant effect on improving the crack resistance of semi-flexible pavement.

\subsection{Influence of matrix porosity}

The semi-flexible pavement matrix mixture is prepared by using matrix grading design curves (void ratio $24 \%, 28 \%$, $32 \%$ ), matrix asphalt and tuff aggregate, and then infused with ordinary cement mortar to form semi-flexible road parts, and conduct low-temperature bending test . The test results are shown in the figure below.

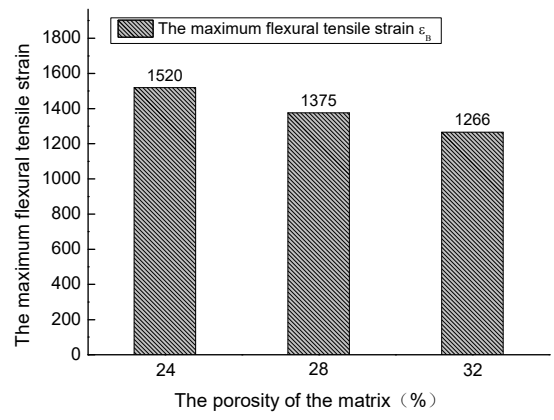

(b) 


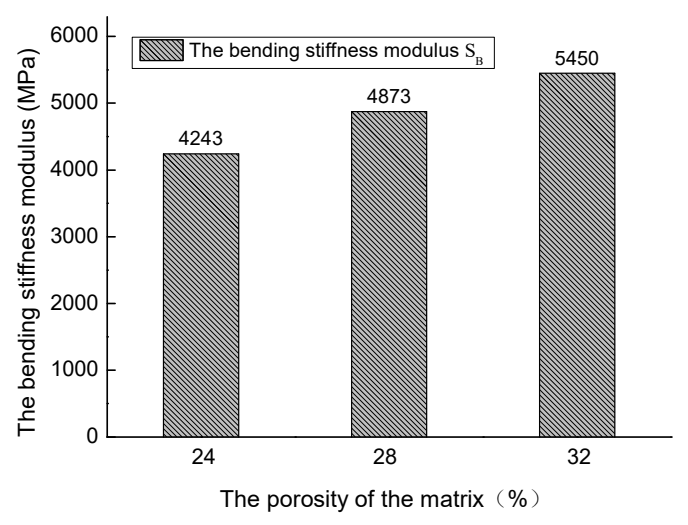

(c)

Figure 2 The results of low temperature bend test

From the data in Figure 2, it can be seen that the porosity of the semi-flexible pavement matrix is different, and the low-temperature bending test data shows differences. The increase of matrix void content will increase the bending tensile strength and bending stiffness modulus of semi-flexible pavement, and the maximum bending tensile strain will decrease slowly. The data shows that the increase of the matrix porosity leads to the gradual decrease of the low-temperature crack resistance of the semi-flexible pavement, which means that the lowtemperature crack resistance of the semi-flexible pavement is the best when the porosity is $24 \%$. The reason is that the porosity of the matrix determines the grouting volume of cement mortar, which has varying degrees of influence on the stiffness modulus of the semi-flexible pavement structure. The larger the volume of cement mortar grouting, the more rigid the overall model of the semi-flexible pavement structure., Resulting in a decrease

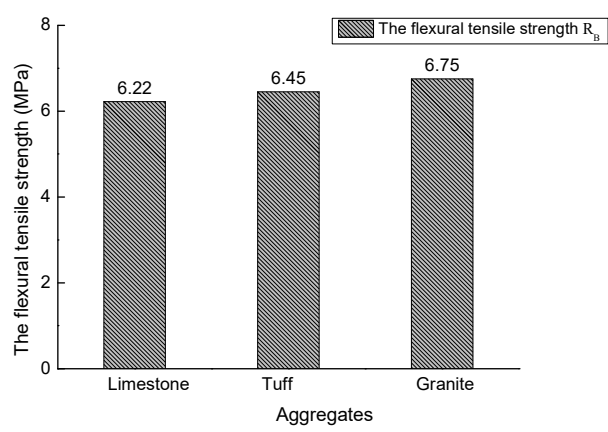

(a) in crack resistance. On the other hand, the porosity increases, the contact interface between the cement mortar and the matrix increases, and there are more stress concentration areas, resulting in an increase in the susceptibility to internal cracking of the semi-flexible pavement structure. Therefore, from the perspective of crack resistance, the porosity of semi-flexible pavement should not be too large.

\subsection{Influence of Aggregate Type}

A gradation curve with a porosity of $24 \%$, matrix asphalt, and aggregates (limestone, tuff, granite) are used to prepare a semi-flexible pavement matrix mixture, and then ordinary cement mortar is poured to form semi-flexible road parts for low-temperature bending tests. The test results are shown in the figure below.

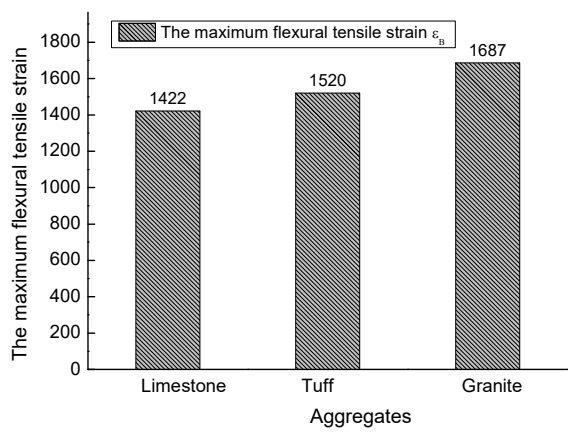

(b) 


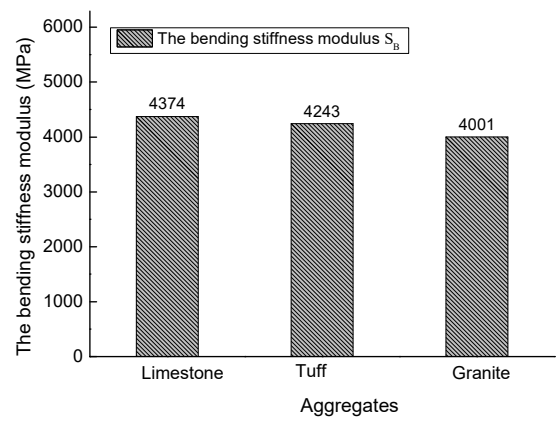

(c)

Figure 3 The results of low temperature bend test

Figure 3 The results of low temperature bend test Different types of aggregates directly lead to different asphalt-aggregate coating effects, which have a certain degree of influence on the internal structure of the semiflexible pavement matrix. It can be seen from Figure 3 that the type of matrix aggregate has a differential impact on the crack resistance of semi-flexible pavement. According to the flexural and tensile strength data, granite is the largest, followed by tuff, and limestone is the smallest. In terms of maximum flexural strain, limestone is the largest, followed by tuff, and granite is the largest. In terms of bending stiffness modulus, limestone is the largest, followed by tuff. Among them, granite is the largest. Considering the above data comprehensively, it can be seen that the semi-flexible pavement of granite aggregate has the best low-temperature crack resistance.

\subsection{Influence of base asphalt type}

A gradation curve with a porosity of $24 \%$, three types of asphalt (base asphalt, SBS modified asphalt, epoxy modified asphalt), tuff aggregates are used to prepare semi-flexible pavement matrix mixture, and then ordinary cement mortar is poured to form semi-flexible Road interview documents, low-temperature bending test. The test results are shown in the figure below.

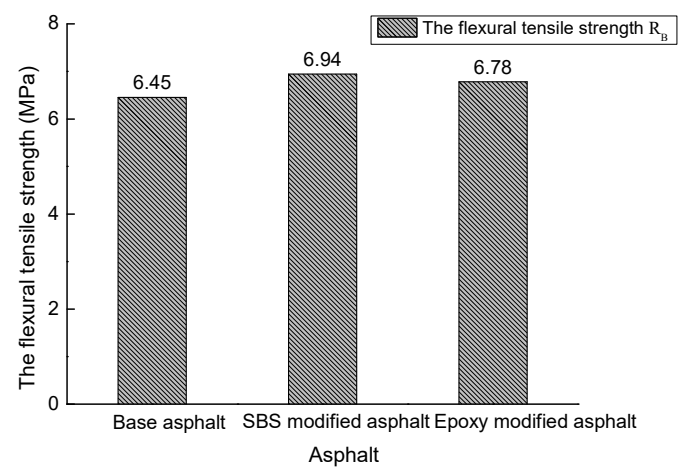

(a)

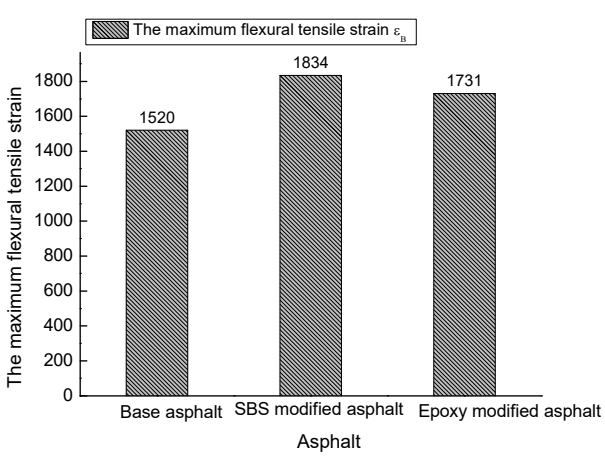

(b)

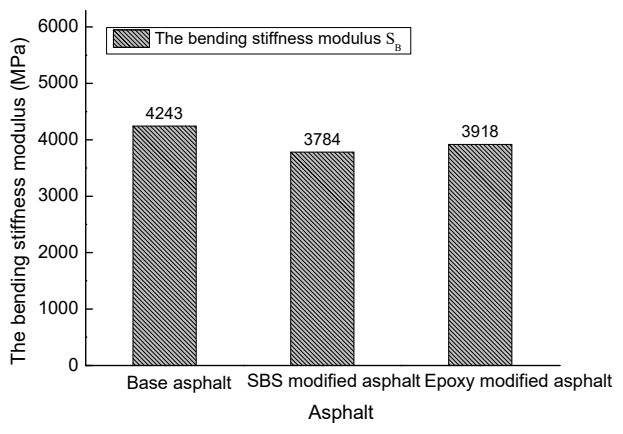

(c)

Figure 4 The results of low temperature bend test 
From the data analysis in Figure 4, it is known that different matrix asphalt types have different degrees of impact on the low-temperature crack resistance of semiflexible pavement. Compared with epoxy modified asphalt and matrix asphalt, when SBS modified asphalt is used as the base asphalt of semi-flexible pavement, the bending tensile strength is the largest, the maximum bending tensile strain is the largest, and the bending stiffness modulus is the smallest. Considering the above data comprehensively, it can be seen that the semi-flexible pavement of SBS modified asphalt has the best low temperature crack resistance. After analyzing the reasons, it is known that the elastoplasticity of the base asphalt is weak, and the low temperature performance is weak. The elastoplasticity of the SBS modified asphalt is strong, and the low temperature performance is better. The rigid modulus of the epoxy modified asphalt is too strong, resulting in low temperature performance. Therefore, the elastoplastic enhancement of the semi-flexible pavement matrix is beneficial to the improvement of low temperature performance.

In summary, influencing factors such as cement mortar type, matrix porosity, matrix asphalt type, matrix aggregate type, etc. have a certain degree of influence on the low-temperature crack resistance of semi-flexible pavement. From the perspective of bending stiffness modulus data, the matrix porosity has the greatest influence on the low-temperature crack resistance, followed by the matrix asphalt type and cement mortar type, and the aggregate type has the least influence. Since the void ratio of the matrix involves the design of semiflexible pavement structure, it should not be changed at will. On the other hand, the improvement of base asphalt often leads to rising cost and poor economy. The performance of cement mortar can be improved by adding external admixtures, and the mixing amount is low, which has little effect on the cost. Therefore, to improve the lowtemperature crack resistance of semi-flexible pavement, we can start with the type of cement mortar, and optimize the performance of cement mortar by screening cement mortar admixtures to improve the low-temperature crack resistance of semi-flexible pavement.

\section{Conclusion}

(1) The orthogonal test method was used to design the cement mortar mix ratio for semi-flexible pavement structure pouring (water-cement ratio 0.7 , mineral powder consumption $8 \%$, sand consumption $16 \%$ ). The fluidity, strength and shrinkage properties of cement mortar were used as evaluation indicators to determine the optimal blending amount of external admixtures (silica fume $6 \%$, emulsified asphalt $4 \%$, water-based epoxy resin $6 \%$ ).

(2) Cement mortar type, matrix void ratio, matrix asphalt type, matrix aggregate type have varying degrees of influence on the crack resistance of semi-flexible pavement materials. Cement mortar admixtures-silica fume and emulsified asphalt can improve the crack resistance of semi-flexible pavement, while water-based epoxy resin reduces the crack resistance of semi-flexible pavement. The smaller the matrix porosity, the stronger the crack resistance of the semi-flexible pavement. The semi-flexible pavement corresponding to SBS modified asphalt and granite aggregate has the best low-temperature crack resistance. Enhancing the flexibility of cement mortar and enhancing the elastoplasticity of the matrix are conducive to improving the low-temperature performance of semi-flexible pavements.

(3) According to the analysis of factors affecting the low-temperature anti-cracking performance of semiflexible pavement, the matrix porosity has the greatest influence on the low-temperature anti-cracking performance, followed by the matrix asphalt type and cement mortar type, and the aggregate type has the least influence. Considering comprehensive performance and economy, it is recommended to optimize the design of cement mortar by screening cement mortar admixtures to improve the crack resistance of semi-flexible pavement. According to the cement mortar admixture used in this article, emulsified asphalt is recommended as the cement mortar admixture.

\section{About the Author:}

Name: Wu Jiahong Sex: Male Date of Birth: 1988-06-15 Education: Bachelor Degree School of Graduation: South China University of Technology

Title: Engineer Research Field: Road Engineering Email: 359704139@qq.com Tel: 15017547305

\section{References}

1. Al-Qadi, I.L., Gouru, H., and Weyers, R.E. (1994). "Asphalt Portland Cement Concrete Composite: Laboratory Evaluation”. J. Transp. Eng., 120(1), 94108.

2. Pei, J., Cai, J., Zou, D., Zhang, J., Li, R., Chen, X., and Jin, L. (2016). "Design and Performance Validation of High-performance Cement Paste as a Grouting Material for Semi-flexible Pavement". Constr. Build. Mater., 126, 206-217.

3. Afonso, M.L., Dinis-Almeida, M., Pereira-deOliveira, L.A., Castro-Gomes, J. and Zoorob, S.E. (2016). "Development of a Semi-flexible Heavy Duty Pavement Surfacing Incorporating Recycled and Waste Aggregates-Preliminary Study". Constr. Build. Mater., 102, 155-161.

4. Cai, J., Pei, J., Luo, Q., Zhang, J., Li, R., and Chen, X. (2017). "Comprehensive Service Properties Evaluation of Composite Grouting Materials with High-performance Cement Paste for Semi-flexible Pavement". Constr. Build. Mater., 153, 544-556.

5. Wang Suqin, Lin Xiuxian, Lou Haixiang. A new type of pavement composite material-research on special asphalt mixture. East China Highway, 1989, (2): 7681.

6. Du, Y., Chen, J., Han, Z., and Liu, W. (2018). "A review on solutions for improving rutting resistance of asphalt pavement and test methods". Constr. Build. 
Mater., 168, 893-905.

7. Gong, M., Xiong, Z., Chen, H., Deng, C., Chen, X., Yang, J., Zhu, H., and Hong, J. (2019). "Evaluation of the cracking resistance of semi-flexible pavement mixture by laboratory research and field validation". Constr. Build. Mater., 168, 893-905

8. Hu Shuguang, Zhang Rongjuan, Ding Qingjun, Huang Shaolong. Research on the performance of semi-flexible pavement with cement mortar. Highway, July 2009, Issue 7.

9. Cai Anlan. Research on the test method and mechanism of high performance cement shrinkage. Doctoral thesis of Nanjing University of Technology, 2005.

10. Huang Chong. Research on volume stability and crack resistance of semi-flexible pavement materials. Master's thesis of Wuhan University of Technology, 2010.

11. Zhang Dake, Growth Celebration, Wu Guoxiong, $\mathrm{Hu}$ Lingling, Zhang Yang. Analysis of Water Stability and Low-temperature Anti-cracking Performance of Semi-flexible Pavement, Journal of Chongqing Jiaotong University, 2007.26(3): 55 57.

12. Wang Weiming, Wu Kuanghuai. Research on crack resistance of semi-flexible pavement materials based on J integral. Highway, 2016: 63 66.

13. Wang D, Liang X, Li D, et al. Study on MechanicsBased Cracking Resistance of Semiflexible Pavement MaterialsJ. Advances in Materials Science and Engineering, 2018, 2018:1-10.

14. "Highway Engineering Cement and Cement Concrete Test Regulations" (JTGE30.2005). Beijing: People's Communications Press.

15. Yang Yuliang, Zou Guilian, Zhang Xiaoning. Research on semi-flexible mixture poured into cement mortar. Highway, November 2002, Issue 11.

16. Liang Xiayi. Experimental study on semi-flexible pavement based on foamed asphalt based warm mix matrix D. South China University of Technology, 2013.

17. Tai Lianhe, Zhang Jiaping. New road building materials. Beijing: Chemical Industry Press, 2003,06.

18. Zhang Xiaoning, Wang Shaohuai, Wu Kuanghuai, Wang Duanyi. CAVF method of asphalt mixture composition designJ. Highway, December 2001, Issue 12: 17-20.

19. Wu Kuanghuai, Zhang Xiaoning. Research and Application of Main Aggregate Void Volume Filling Method for Asphalt Mixture DesignJ.

20. Li Wenzhen, Li Liang, Zeng Wei. Research on lowtemperature crack resistance and bending test of asphalt mixture. Special Structure Supplement 21 Jia Jingpeng. Research on low-temperature crack resistance of high-performance asphalt mixture. Master Thesis of Chongqing Jiaotong University, 2008. 